\title{
Some Parameter Boundaries Governing Microgravity Pool Boiling Modes
}

\author{
HERMAN MERTE, JR. \\ University of Michigan, Ann Arbor, Michigan 48109-2125, USA
}

\begin{abstract}
Pool boiling experiments were conducted in microgravity on five space shuttle flights, using a flat plate heater consisting of a semitransparent thin gold film deposited on a quartz substrate that also acted as a resistance thermometer. The test fluid was $R-113$, and the vapor bubble behavior at the heater surface was photographed from beneath as well as from the side. Each flight consisted of a matrix of three levels of imposed heat flux and three levels of initial bulk liquid subcooling. In many of the total of 45 experiments, steady nucleate boiling was observed from 16-mm movie films, where a large vapor bubble formed and remained slightly removed from the heater surface, with small vapor bubbles growing on the heater surface, and on contact coalescing with the large bubble. Computations of the forces associated with the momentum transfer in this process, which counters the Marangoni convection effects tending to impel the large bubble toward the heater surface, have been completed for all cases where applicable. The modes of pool boiling observed with successive increases in levels of heat flux in microgravity are categorized as: (i) minimum or incipient nucleate boiling; (ii) nucleate boiling with vigorous motion of the bubbles adjacent and parallel to the heater surface, impelled by Marangoni convection effects; (iii) nucleate boiling followed by coalescence with a neighboring large vapor bubble; (iv) partial dryout of the heater surface, in parallel with nucleate boiling; (v) complete dryout. The boundaries between these modes are delineated graphically as a function of the imposed heat flux and initial bulk liquid subcooling, together with the levels of the forces holding the large bubbles, acting as vapor reservoirs, away from the heater surface for the steady nucleate boiling mode.
\end{abstract}

KEYWORDS: microgravity; momentum effects; pool boiling

\section{INTRODUCTION}

The availability of long-term high-quality microgravity associated with space flight provided opportunities for the study of pool boiling under this

Address for correspondence: Herman Merte, Jr., Department of Mechanical Engineering, 2026 G.G. Brown Building, University of Michigan, Ann Arbor, MI 48109-2125. Voice: 734-764-5240; fax: 734647-3170.

e-mail: merte@umich.edu

Ann. N.Y. Acad. Sci. 1077: 629-649 (2006). (C) 2006 New York Academy of Sciences.

doi: 10.1196/annals.1362.017 
condition, resulting in some insights into its behavior not encountered in Earth gravity. As has been extensively and well demonstrated over the years, the phenomena of nucleate or bubble boiling, including both pool and flowing, are highly complex, resisting attempts to describe or predict their behavior under the variety of parameters to which they may be subjected in applications. Considerable progress has been made in this regard, and is expected to continue in light of advances in measurement and computational capabilities. However, it should be recognized that the current lack of adequate understanding of the mechanisms involved continues to severely inhibit the capacity for modeling, and therefore for computation. Hence, the necessity for experiments both accompanied and followed by analytical activities for purposes of confirmation.

Pool boiling experiments were conducted on five space shuttle flights as part of the NASA Get Away Special (GAS) program during the period of 19921996. Detailed descriptions of the hardware, procedures and general results are given elsewhere. ${ }^{1,2} \mathrm{~A}$ brief description of the hardware is repeated in the following section.

Two identical facilities resulted from the development of the experiment, a prototype and a flight version. Each flight experiment consisted of three levels of input heat flux and three levels of initial liquid subcooling, for a total of nine different test runs per flight. The nominal variable parameters associated with each flight are given in TABLE 1 . These were identical in the first three flights except for minor changes in timing of the camera speeds. These three flights are of special significance in that any questions as to the reproducibility of unexpected behaviors are answered: The first and third are identical experiments with identical hardware; the first and second (or second and third) are identical experiments with different hardware of identical construction. For the fourth and fifth flights, the opportunities were taken to increase the levels of subcooling and to decrease the imposed input heat flux, respectively. Viewing the first three flights as one, one experiment in each flight employed the same parameters between the third, fourth, and fifth flights in order to confirm reproducibility within the last two flights.

The original objective of the study of boiling in microgravity was that of flow boiling, because of the potentially large number of future applications.

TABLE 1. Nominal variable parameters used for pool boiling experiments

\begin{tabular}{lccl}
\hline Shuttle flight & $\begin{array}{c}\text { Initial bulk } \\
\text { liquid subcooling, }{ }^{\circ} \mathrm{C}\end{array}$ & $\begin{array}{c}\text { Imposed heat flux to } \\
\text { film heater, - W/cm }{ }^{2}\end{array}$ & Hardware \\
\hline STS-47 & $11.1-2.8-0.3$ & $8-4-2$ & Prototype \\
STS-57 & $11.1-2.8-0.3$ & $8-4-2$ & Flight \\
STS-60 & $11.1-2.8-0.3$ & $8-4-2$ & Prototype \\
STS-72 & $22.2-16.7-11.1$ & $8-4-2$ & Flight \\
STS-77 & $11.1-2.8-0.3$ & $2-1-0.5$ & Flight \\
\hline
\end{tabular}




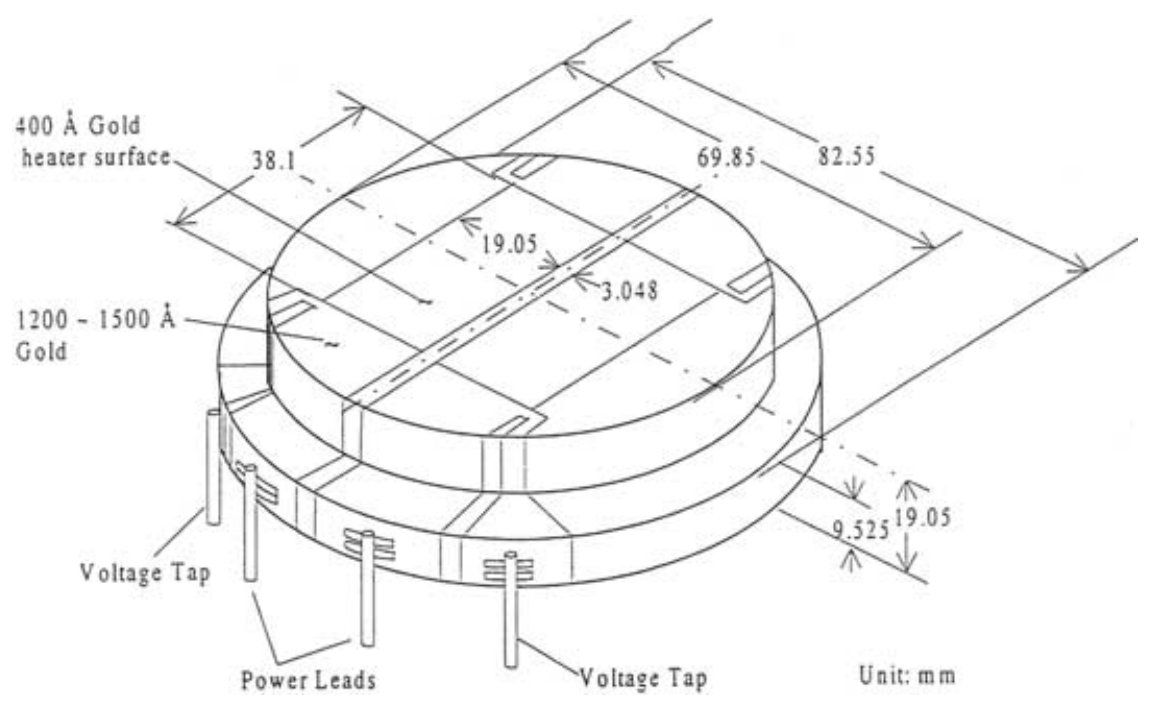

FIGURE 1. Transparent gold film heater/resistance thermometer on quartz substrate.

It became obvious early on that the possibility for realistic size flow boiling experiments under long-term microgravity was some 15-20 years in the future because of other demands on the resources required. The availability of the GAS containers in the then newly available space shuttles became an attractive opportunity, provided the existing size and power constraints were satisfied. These could be met in practical terms only with pool boiling, and was accepted as a satisfactory initial study, because the limit of zero imposed velocity in flow boiling constitutes pool boiling. A constraint attendant with the GAS container was the lack of a heat sink, necessary to achieve true steady operation with any thermal process. A reasonable compromise was reached by limiting each individual experiment to on the order of $2 \mathrm{~min}$. Nevertheless, the lack of a heat sink should be considered when interpreting the individual physical phenomena observed, and will be pointed out below when appropriate.

In 26 of the total of 45 experiments $(9 \times 5)$, conditions of what can be termed as steady-state pool boiling were surprisingly achieved during the 2 min generally allocated for each experiment. In all of these, the boiling was associated with the formation, growth, and motion of relatively small vapor bubbles, giving rise to average heat transfer coefficients often greater than that in Earth gravity, as presented elsewhere. ${ }^{3,4}$ In 16 of the 45 experiments, continuous temperature rises of the heater surface occurred resulting from the dryout. Dryout of the heater surface took place in all cases, with the highest input heat flux of $q^{\prime \prime}=8 \mathrm{~W} / \mathrm{cm}^{2}$, except when the largest bulk liquid subcooling of $22.2^{\circ} \mathrm{C}$ was applied in the STS-72 flight. As described in Lee et al. ${ }^{4}$ highly effective steady-state boiling takes place when a large vapor bubble slightly removed 


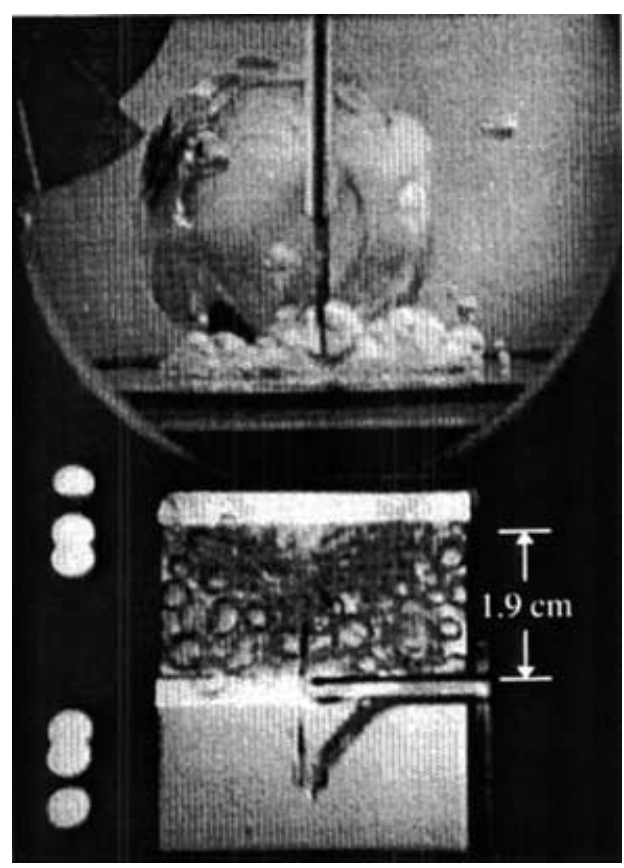

FIGURE 2. Representative photograph of steady nucleate pool boiling in microgravity. STS-60 Run $\# 2, q=4 \mathrm{~W} / \mathrm{cm}^{2}, \Delta T_{\text {sub }}=11.1^{\circ} \mathrm{C}$. Frame $\# 1329$. Time $=51.23 \mathrm{sec}$.

from the heater surface is present to act as a reservoir for the small bubbles growing beneath, thereby inhibiting the onset of dryout. This behavior took place with the combination of the moderate heat flux levels of 4 and $2 \mathrm{~W} / \mathrm{cm}^{2}$ and subcoolings below $16.7^{\circ} \mathrm{C}$ (TABLE 1). Increasing the subcooling to $22.2^{\circ} \mathrm{C}$ eliminated the formation of a large vapor bubble, but still produced highly effective steady boiling because of thermocapillary effects, ${ }^{5}$ with a technical basis presented most recently in Betz and Straub ${ }^{6}$ and by Sides. ${ }^{7}$ In the remaining 3 of the 45 experiments, either little or no nucleate boiling took place because of the combinations of low heat flux input and higher initial liquid subcooling. All 45 of the experiments are listed in the APPENDIX, identified by the STS Run Numbers and associated nominal levels of input heat flux and initial liquid subcooling. The remaining parameters included therein will be described below.

The objective of the present article is to provide the complete quantitative results that serve to explain the unexpected behaviors observed and described above, producing the steady microgravity nucleate pool boiling. In the majority of these, a large vapor bubble slightly removed from the heater surface acts as a reservoir for the small bubbles growing beneath. According to the theories of thermocapillarity, such a large vapor bubble should be impelled toward the 


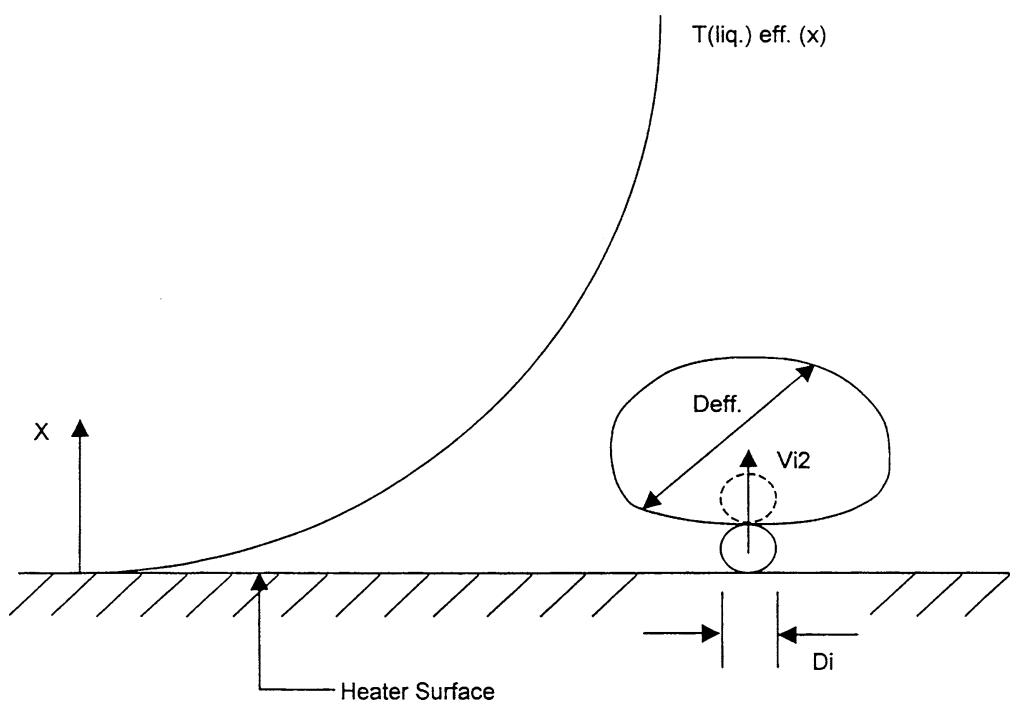

FIGURE 3. Model for sustaining large vapor bubble away from heater surface in microgravity to counter thermocapillarity.

heated surface, resulting in dryout and unsteady behavior. The mechanistic elements that inhibit this process are presented in the following sections, together with order-of-magnitude estimates of the forces involved, as determined from the space experiments. Summaries of these forces are given in the Appendix, together with those provided in detail previously. ${ }^{8}$ In addition, the boundaries between the various modes of pool boiling observed in microgravity will be delineated graphically as a function of the imposed heat flux and initial bulk

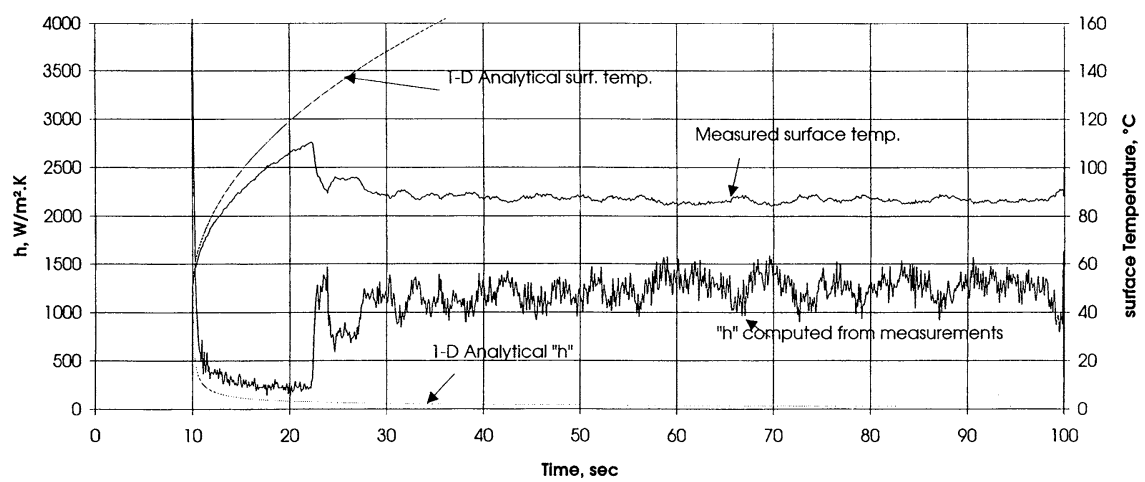

FIGURE 4. Mean heater surface temperature and heat transfer coefficient: STS-47 Run $\# 2, q=2 \mathrm{~W} / \mathrm{cm}^{2}, \Delta T_{\text {sub }}=11.1^{\circ} \mathrm{C}$. 


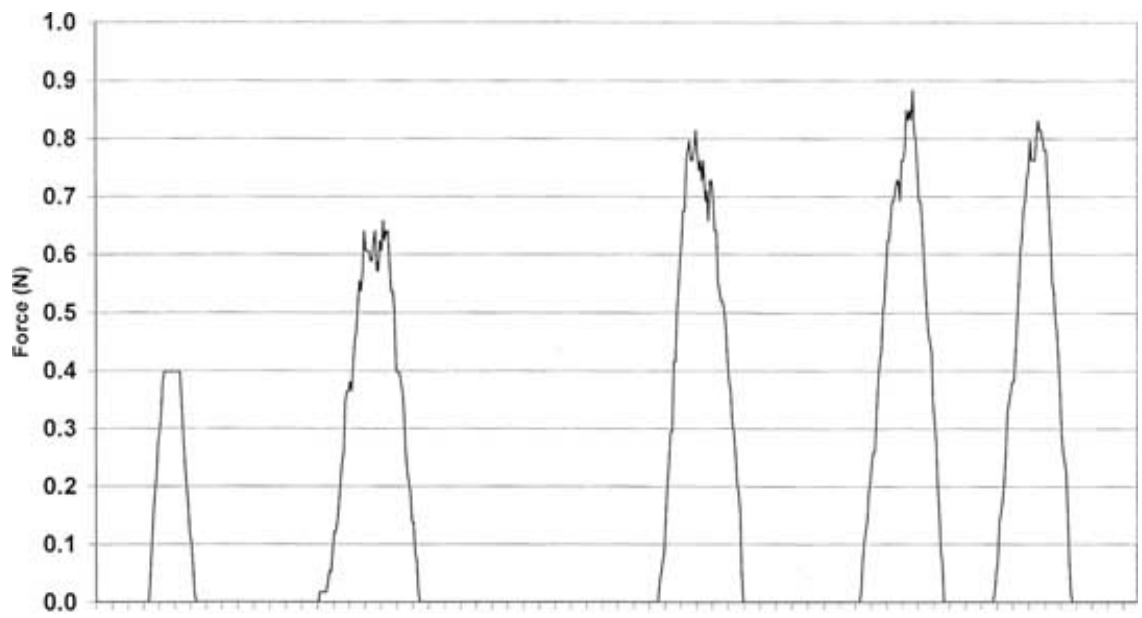

ข้ Time (s)

FIGURE 5. Lift-off force induced by engulfed bubbles: STS-47 Run $\# 2, q=2 \mathrm{~W} / \mathrm{cm}^{2}$, $\Delta T_{\text {sub }}=11.1^{\circ} \mathrm{C}$.

liquid subcooling, together with the levels of the forces holding the large vapor bubbles away from the heater surface.

\section{DESCRIPTION OF EXPERIMENTAL HARDWARE}

As seen in FIGURE 1, two heater surfaces are placed on a single flat substrate, with one acting as a backup, and are installed so as to form one wall of the

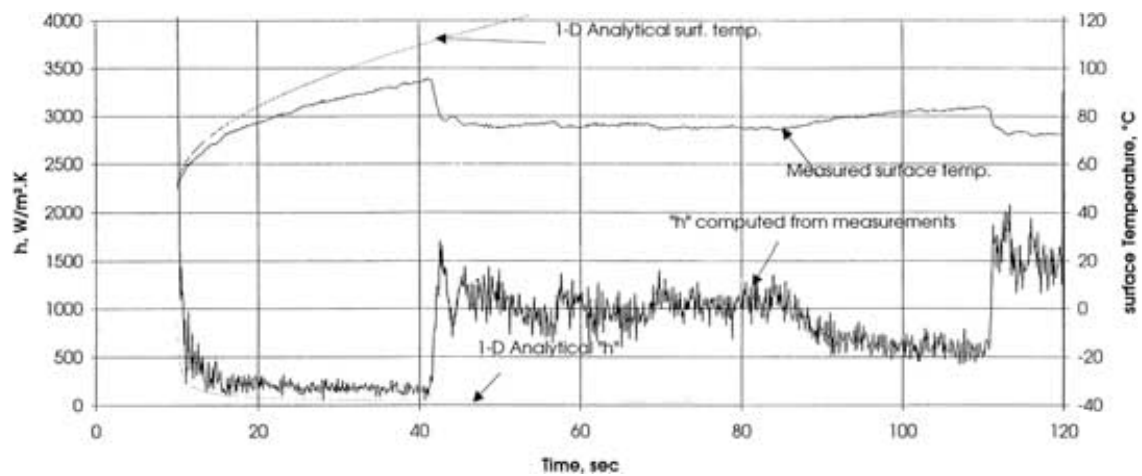

FIGURE 6. Mean heater surface temperature and heat transfer coefficient: STS-47 Run \# 3, $q=2 \mathrm{~W} / \mathrm{cm}^{2}, \Delta T_{\text {sub }}=11.1^{\circ} \mathrm{C}$. 


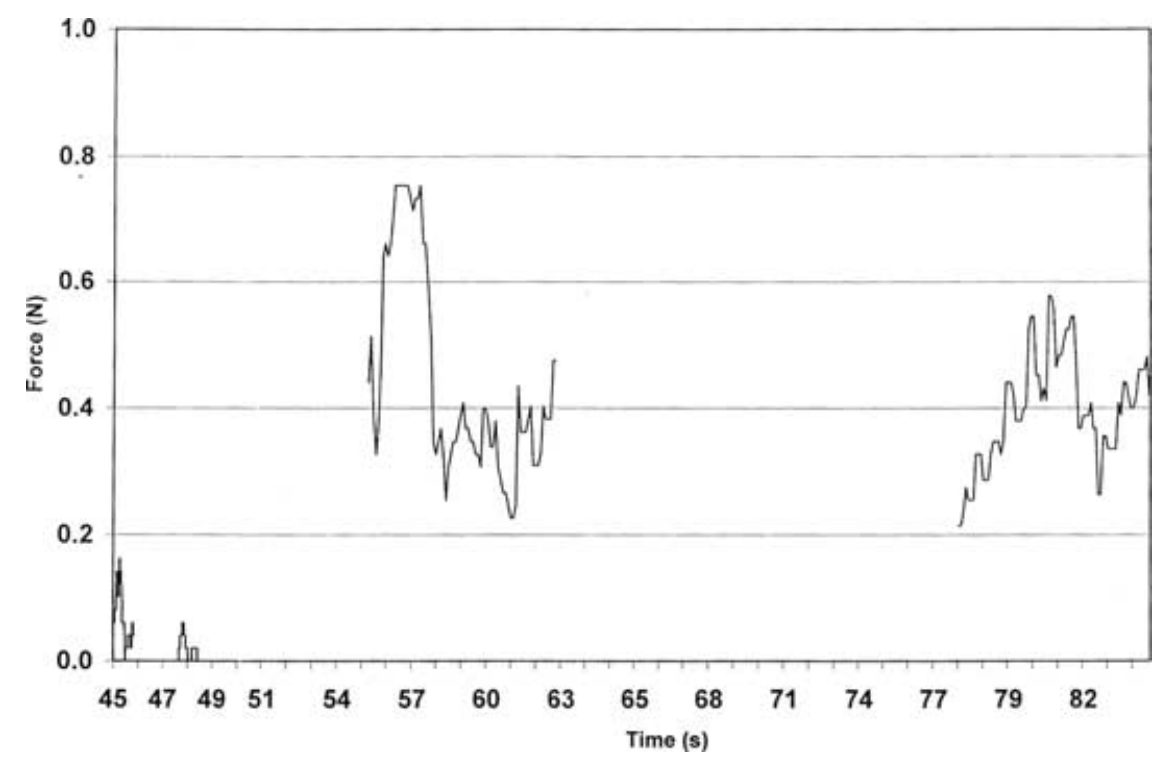

FIGURE 7. Lift-off force induced by engulfed bubbles: STS-47 Run $\# 3, q=2 \mathrm{~W} / \mathrm{cm}^{2}$, $\Delta T_{\text {sub }}=11.1^{\circ} \mathrm{C}$.

test vessel having internal dimensions of $15.2 \mathrm{~cm}$ in diameter by $10.2 \mathrm{~cm}$ high. Each heater consists of a 400 - $\AA$-thick semitransparent gold film sputtered on a highly polished quartz substrate, and serves simultaneously as a heater, with an uncertainty of $\pm 2 \%$ in the heat flux, and a resistance thermometer, with an overall uncertainty of $\pm 1.0^{\circ} \mathrm{C}$ in the mean surface temperature. The heater is rectangular, $19.05 \times 38.1 \mathrm{~mm}(0.75 \times 1.5 \mathrm{inch})$. System subcooling is obtained by increasing the system pressure above the saturation pressure and is controlled and measured with an uncertainty of $\pm 0.345 \mathrm{kPa}$. Degassed commercial grade R-113 was used because of its electrical nonconductivity, compatible for direct contact with the thin gold film heater.

In light of the propensity for the R-113 to absorb large amounts of gases, considerable efforts were expended to reduce the dissolved gases to the lowest practical level, thereby minimizing the thermocapillary convection around bubbles containing mixtures of gas and vapor. ${ }^{6}$ The R-113 was purified and degassed by a double distillation process, a molecular sieve and freezing on a highly convoluted surface at liquid nitrogen temperature levels, while continuously pumping out at a low pressure. The degassing was deemed adequate when the measured vapor pressure conformed to the equation of Mastroianni et al. ${ }^{9}$ within the accuracy of the standard laboratory instruments $\left( \pm 0.06^{\circ} \mathrm{C}\right.$, $\pm 170 \mathrm{~Pa}$ ) over the temperature range used.

Photographs of the boiling process were obtained simultaneously from the side and from beneath the heater surface at framing rates of 10 and $100 \mathrm{fps}$, with a 16-mm cine camera. A sample is given in FIGURE 2. 


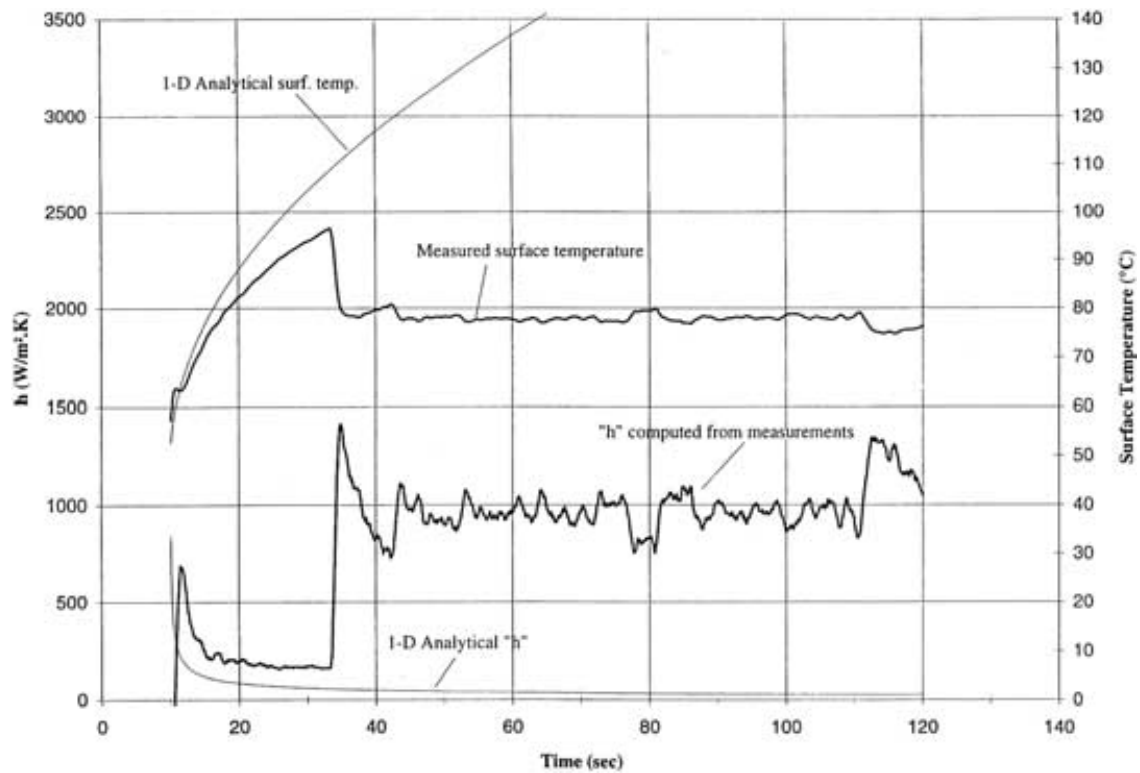

FIGURE 8. Mean heater surface temperature and heat transfer coefficient: STS-57 Run \#3, $q=2 \mathrm{~W} / \mathrm{cm}^{2}, \Delta T_{\text {sub }}=11.1^{\circ} \mathrm{C}$.

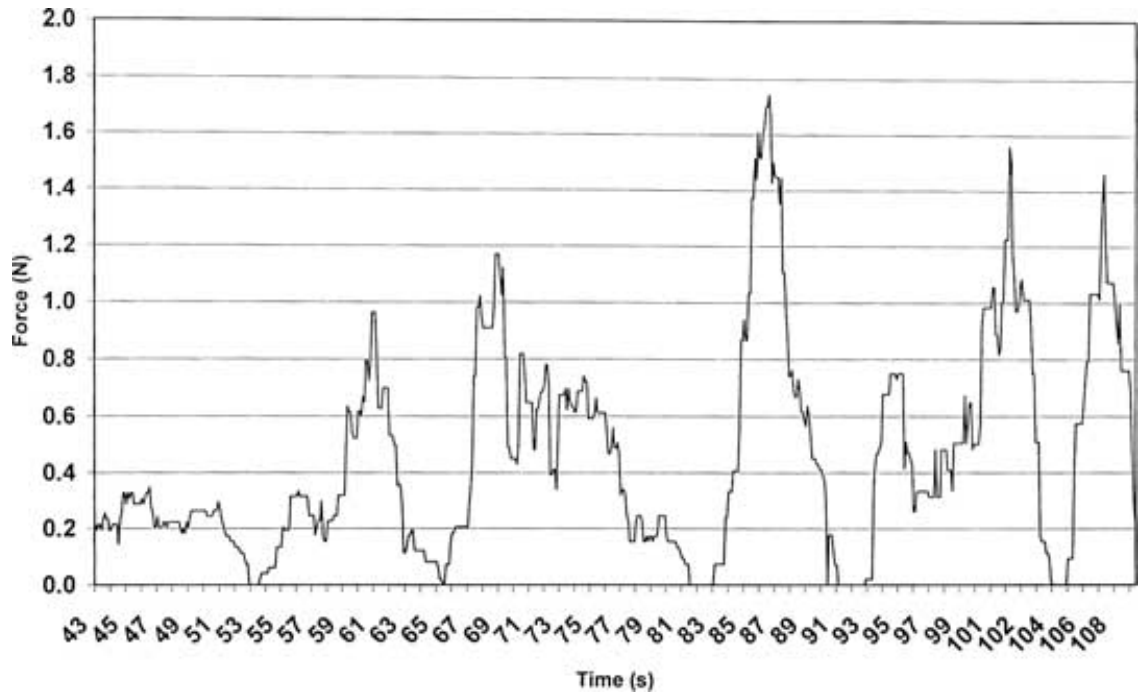

FIGURE 9. Lift-off force induced by engulfed bubbles: STS-57 Run $\# 3, q=2 \mathrm{~W} / \mathrm{cm}^{2}$, $\Delta T_{\text {sub }}=11.1^{\circ} \mathrm{C}$. 


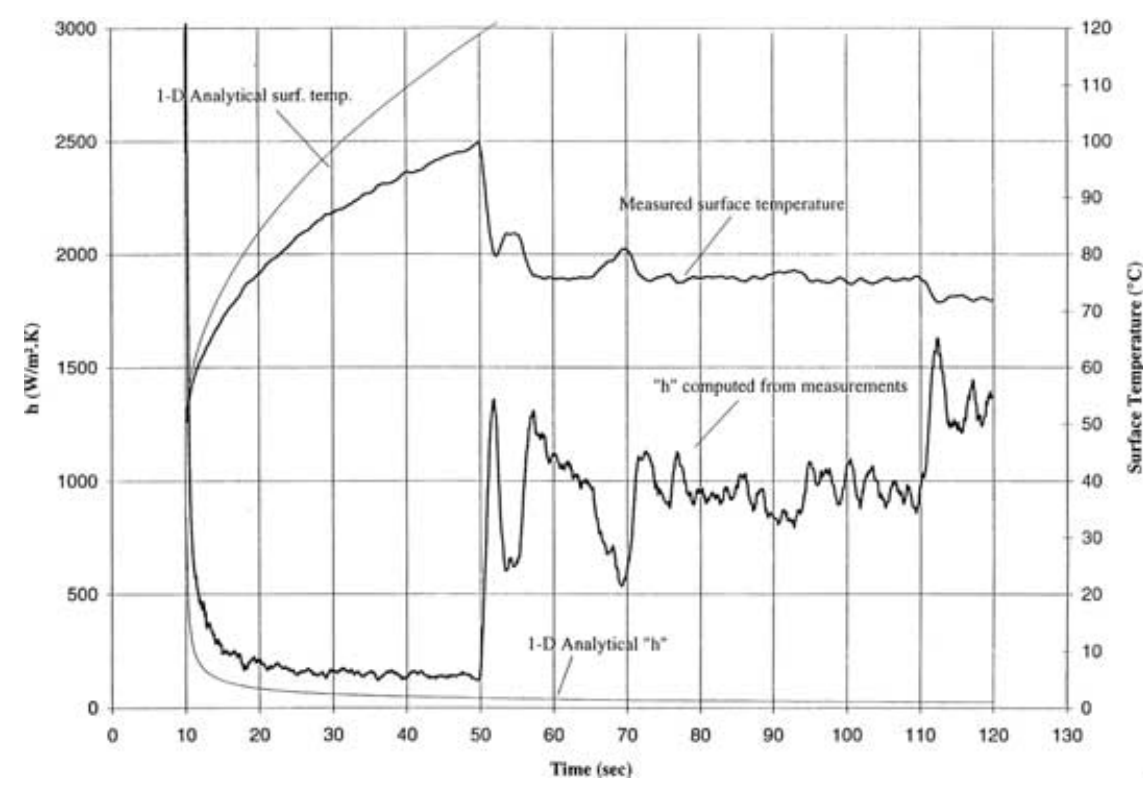

FIGURE 10. Mean heater surface temperature and heat transfer coefficient: STS-60 Run \#3, $q=2 \mathrm{~W} / \mathrm{cm}^{2}, \Delta T_{\text {sub }}=11.1^{\circ} \mathrm{C}$.

\section{ANALYSIS}

FigURE 3 is a schematic of the representative photograph in FigURE 2 in which a relatively large vapor bubble is maintained off the heater surface, in opposition to the thermocapillary forces, which otherwise would move this bubble toward the heated surface, producing dryout as described in the previous section. This opposing force is ascribed to the momentum of the small bubbles nucleating and growing beneath the large ones, arising from the conversion of surface energy to kinetic energy as the small bubbles combine with the large one. Holding the large bubbles away from the heater surface permits liquid inflow beneath, producing the resulting steady nucleate boiling observed.

From measurements of the size of the small bubbles as they combine with the larger ones, and the frequency of this process, it is possible to estimate the order of magnitude of the forces involved, which at some future time might be compared with predictions of the associated thermocapillary forces.

For a vapor bubble of diameter $D_{i}$ at the moment of combination with the large hovering vapor bubble near the heater surface, at which point the bubble of diameter $D_{i}$ "disappeared" from the field of view, the surface energy per bubble is converted to kinetic energy. The associated momentum transfer or force acting on the large hovering vapor bubble is determined using the measured mean bubble frequency $\bar{f}_{i}$ for size " $i$," then summing over all bubble sizes with the result given as 


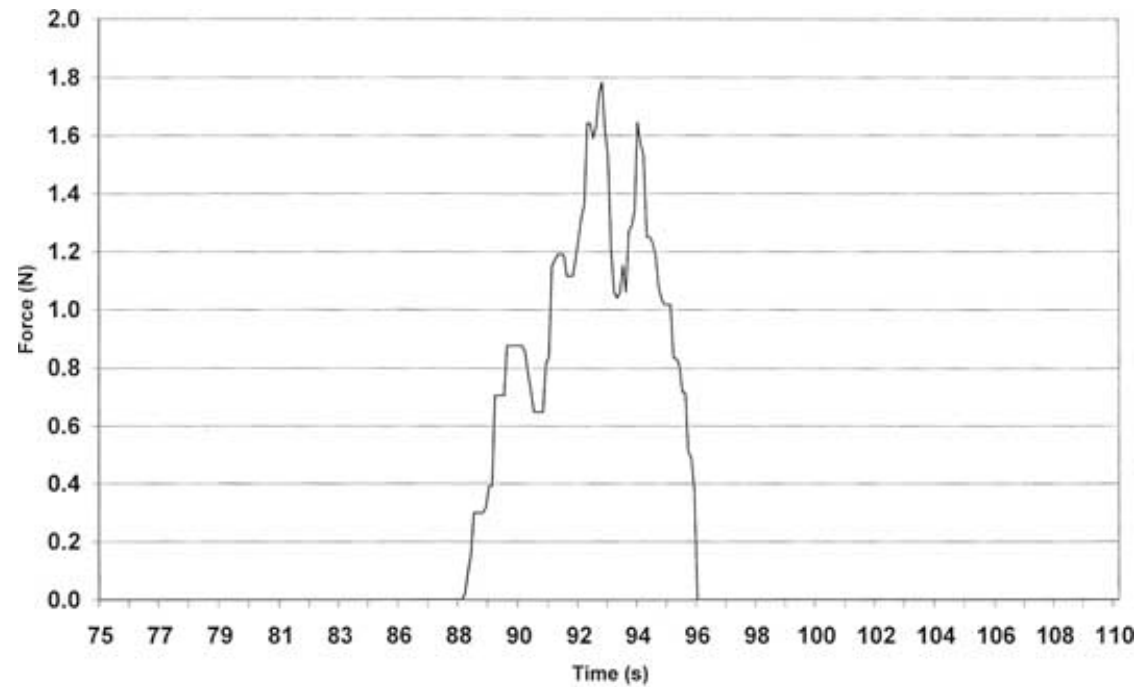

FIGURE 11. Lift-off force induced by engulfed bubbles: STS-60 Run \#3, $q=2$ $\mathrm{W} / \mathrm{cm}^{2}, \Delta T_{\text {sub }}=11.1^{\circ} \mathrm{C}$.

$$
F_{t}=\pi \sum_{i=1}^{n_{t}} \bar{f} \times\left(\frac{\sigma_{i} \times \rho_{v i}}{3}\right)^{1 / 2} \times D_{i}^{5 / 2}
$$

The detailed development of Equation (1) and related assumptions are given elsewhere. ${ }^{8}$ It was noted that the vapor bubble generation rate at any particular

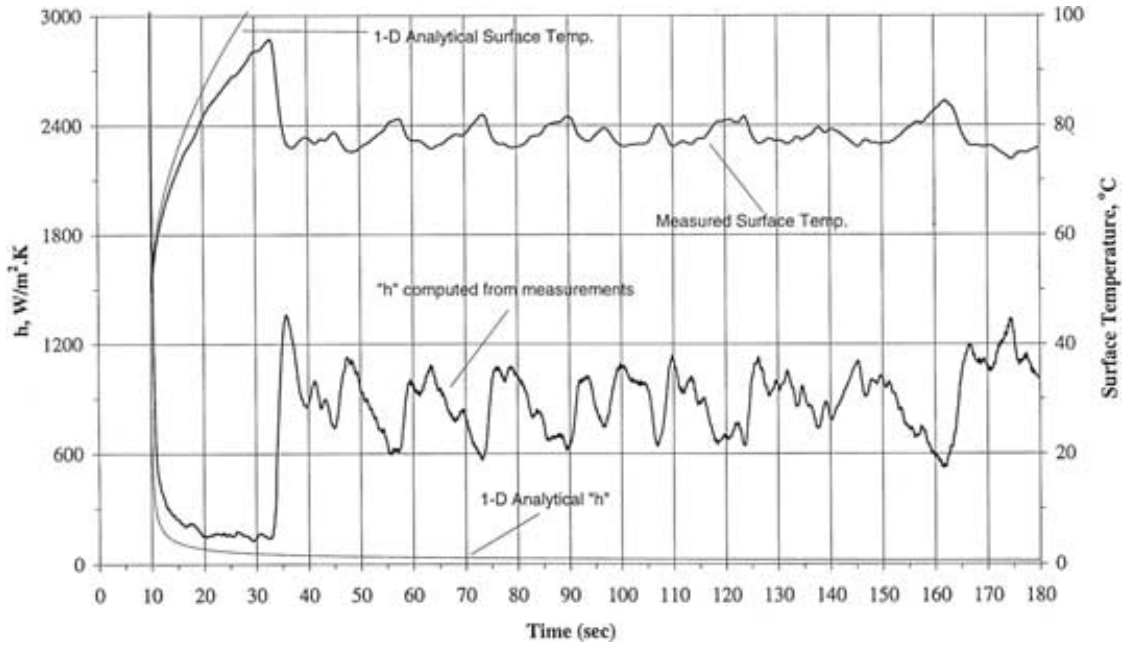

FIGURE 12. Mean heater surface temperature and heat transfer coefficient: STS-77 Run $\# 1, q=2 \mathrm{~W} / \mathrm{cm}^{2}, \Delta T_{\text {sub }}=11.1^{\circ} \mathrm{C}$. 


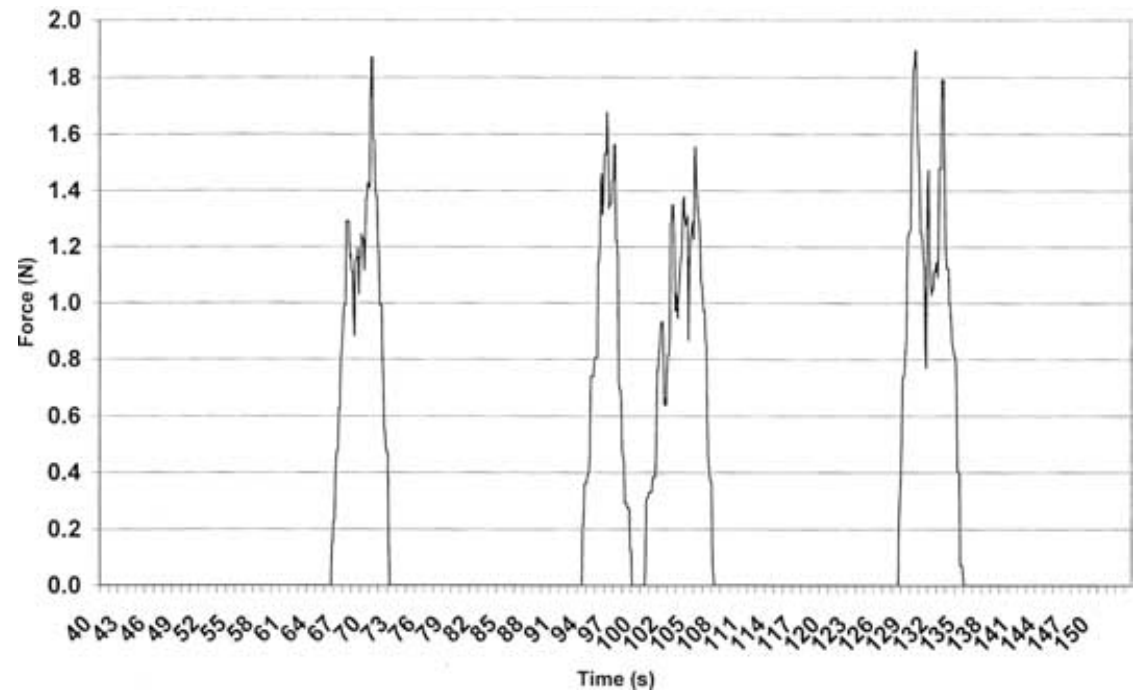

FIGURE 13. Lift-off force induced by engulfed bubbles: STS-77 Run \#1, $q=2$ $\mathrm{W} / \mathrm{cm}^{2}, \Delta T_{\text {sub }}=11.1^{\circ} \mathrm{C}$.

physical location on the heater surface was never faster than the film framing rate used here, $10 \mathrm{pps}$, which means that all "disappearing" bubbles of size $D_{i}$ could be observed and counted with reasonable certainty. It was found to be adequate to count the "disappearing" bubble within only four size ranges " $i$ " in

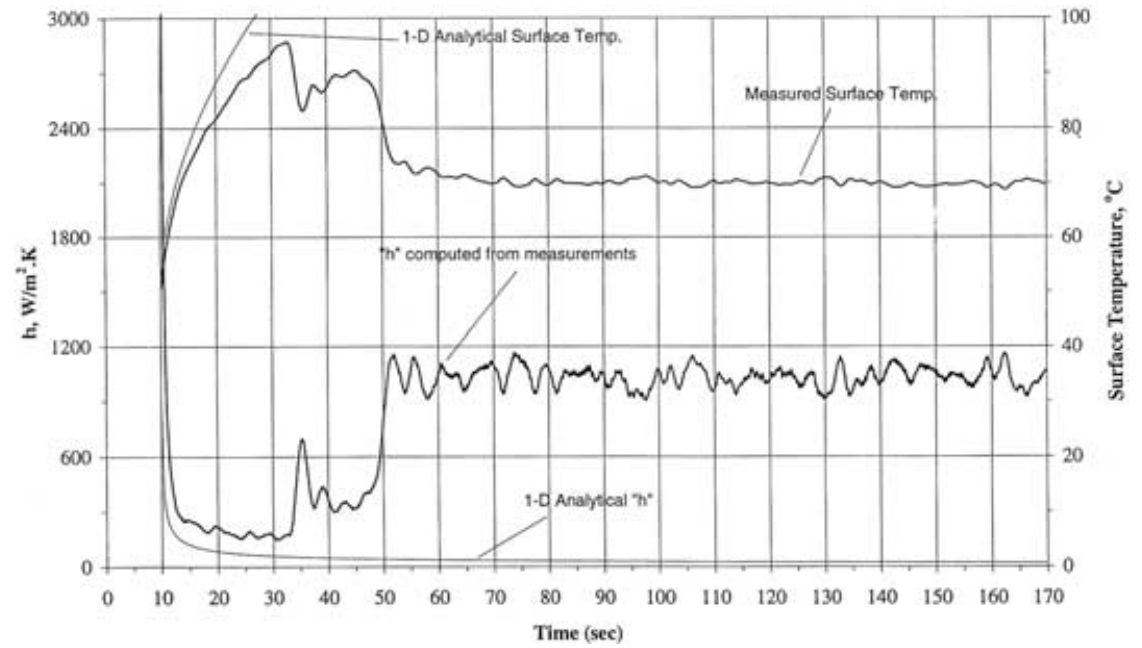

FIGURE 14. Mean heater surface temperature and heat transfer coefficient: STS-77 Run\#4, $q=2 \mathrm{~W} / \mathrm{cm}^{2}, \Delta T_{\text {sub }}=3^{\circ} \mathrm{C}$. 


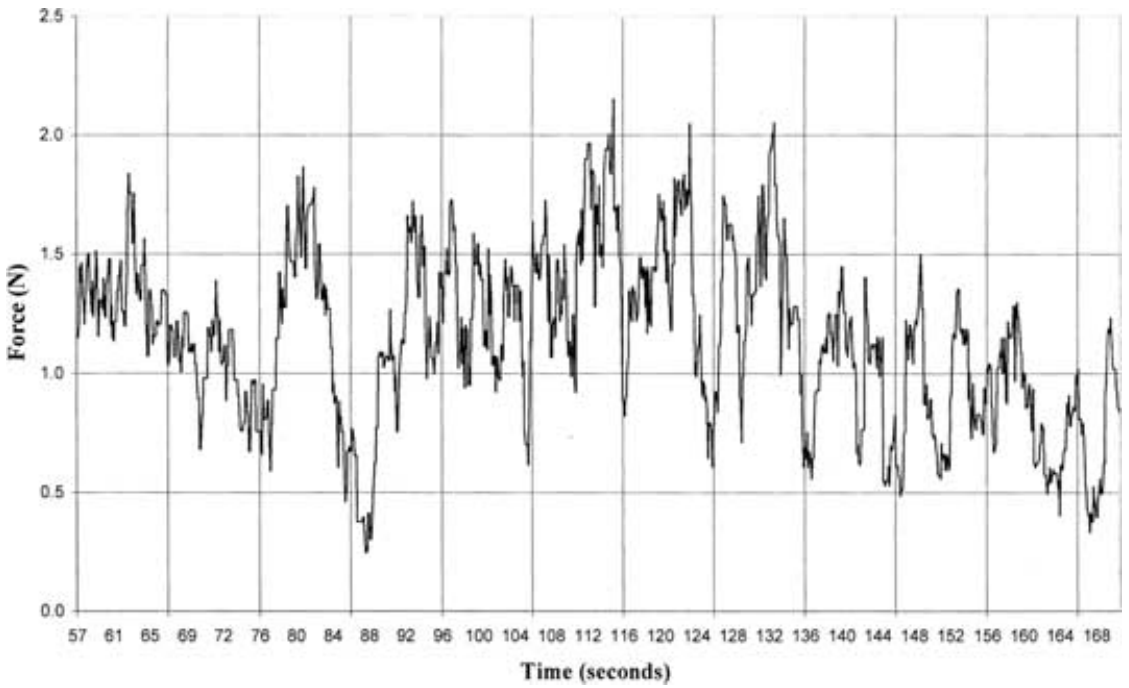

FIGURE 15. Lift-off force induced by engulfed bubbles: STS-77 Run \#4, $q=2$ $\mathrm{W} / \mathrm{cm}^{2}, \Delta T_{\text {sub }}=3^{\circ} \mathrm{C}$.

each frame, with diameters between 2-4 mm, 4-6 mm, 6-8 mm, and 8-10 $\mathrm{mm}$, and then using the mean diameter within each of these ranges in Equation (1). The mean frequencies of each of these four size ranges were determined by averaging each over $\pm 1 \mathrm{sec}$ ( \pm 10 frames) for each time of interest, and then

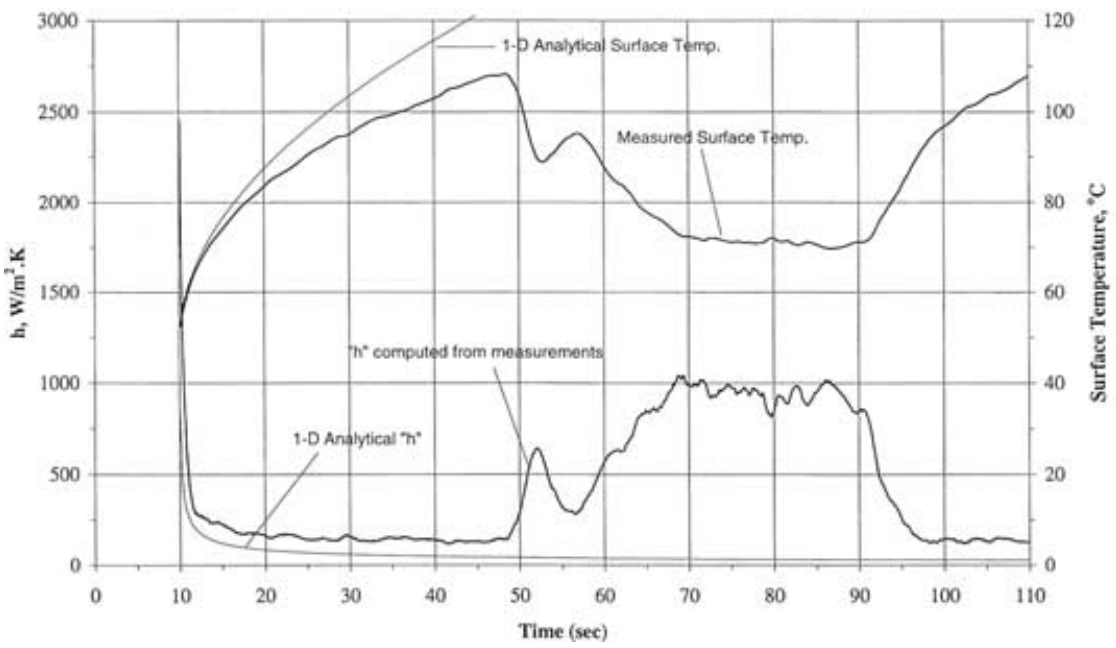

FIGURE 16. Mean heater surface temperature and heat transfer coefficient: STS-77 Run \#7, $q=2 \mathrm{~W} / \mathrm{cm}^{2}, \Delta T_{\text {sub }}=0.3^{\circ} \mathrm{C}$. 


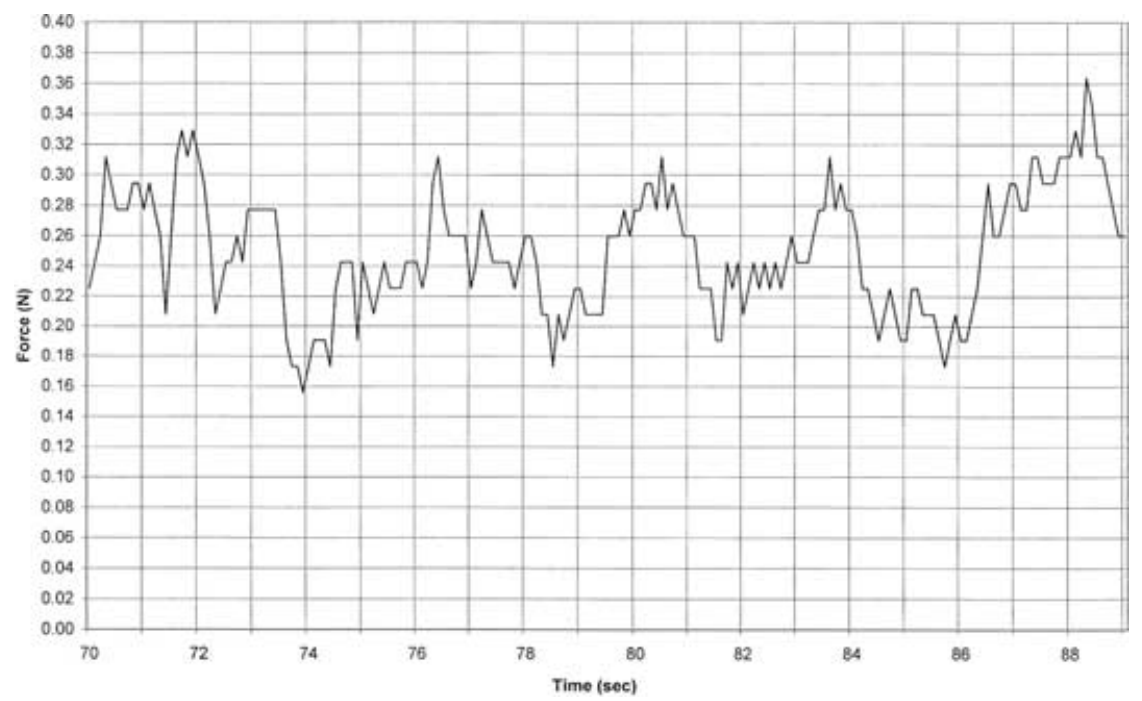

FIGURE 17. Lift-off force induced by engulfed bubbles: STS-77 Run \#7, $q=2$ $\mathrm{W} / \mathrm{cm}^{2}, \Delta T_{\text {sub }}=0.3^{\circ} \mathrm{C}$.

advancing one frame at a time over the entire period of interest. Computation of the time-varying forces induced by the "disappearing" bubbles on the large hovering bubbles were then carried out using Equation (1).

\section{RESULTS}

The computations presented previously ${ }^{8}$ of the forces using Equation (1), which maintained the relatively large vapor bubbles away from the heater surface in opposition to the prevailing thermocapillary forces, were then selected for the initial presentation based on the attributes they shared:

1. The nucleate boiling was consistent, with no partial dryouts, during the general time periods of $2 \mathrm{~min}$ for each test.

2. These all collectively produced the highest levels of the mean heat transfer coefficients.

3. The computed lift-off forces were time-varying in some cases, but the maximum levels in each were the highest obtained, together with the mean heat transfer coefficients stated above.

The relationship between the imposed heat flux and initial bulk liquid subcooling that produce the differences in behavior observed in the previous work ${ }^{8}$ 


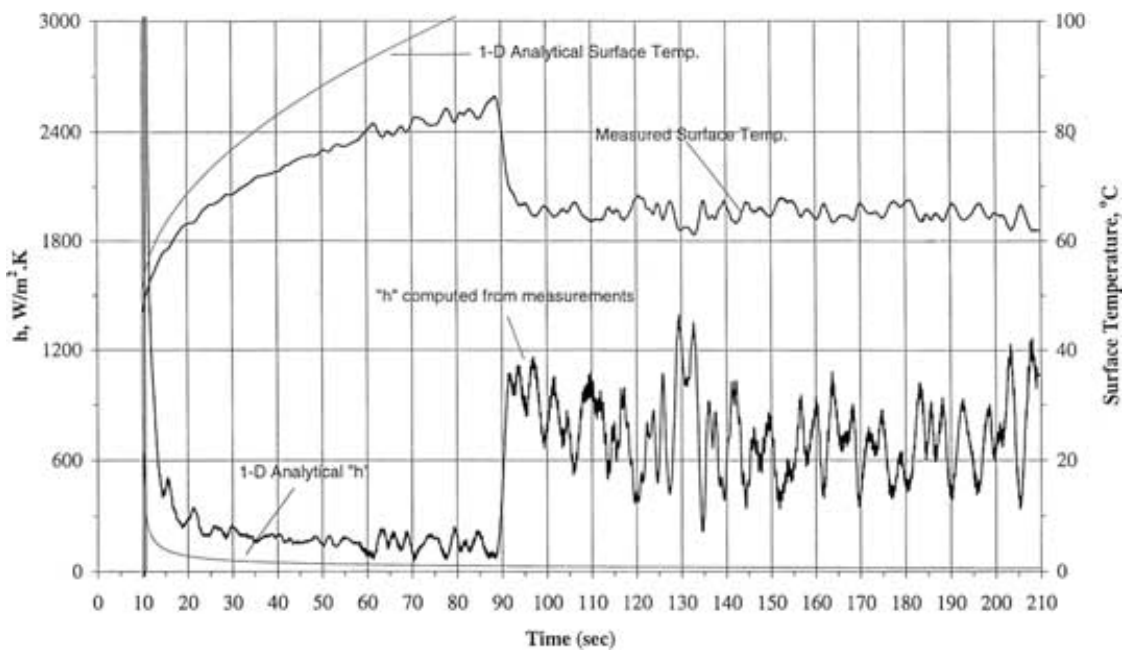

FIGURE 18. Mean heater surface temperature and heat transfer coefficient: STS-77 Run $\# 5, q=1 \mathrm{~W} / \mathrm{cm}^{2}, \Delta T_{\text {sub }}=3^{\circ} \mathrm{C}$.

and that are to be presented here will become obvious in the last figure given below. It should be pointed out that a typographical error exists in the title of Figure 18 of our previous work. ${ }^{8}$ The imposed heat flux should read $4 \mathrm{~W} / \mathrm{cm}^{2}$ (not $2 \mathrm{~W} / \mathrm{cm}^{2}$ ). However, the conclusions in the first full paragraph on page 214 of that article are correct.

In evaluating the contributions of each of the four "engulfed" bubble size ranges to the lift-off forces, it was determined for all the cases below, consistent with the previous results, that the smallest engulfing bubbles provided the largest contributions, decreasing as the diameters increased.

The results of the remaining nine tests for which it was possible to evaluate the relative lift-off forces are given below in the same order as that used previously ${ }^{8}$ except for the first four tests, ${ }^{8}$ which were intended to explain the processes and the reproducibility. These are grouped first together in decreasing imposed heat flux levels, and then within each heat flux level in decreasing initial bulk liquid subcoolings, as appropriate. In contrast to the shared attributes listed above for the tests presented previously ${ }^{8}$, it would be deduced from the photographs, the associated mean heat transfer coefficients, and the computed lift-off forces that:

1. The nucleate boiling was at times quite inconsistent, with partial dryouts occurring at various times over different parts of the $2 \times 1$ rectangular heater surface.

2. The mean heat transfer coefficients were reduced at times because of the partial dryouts. 


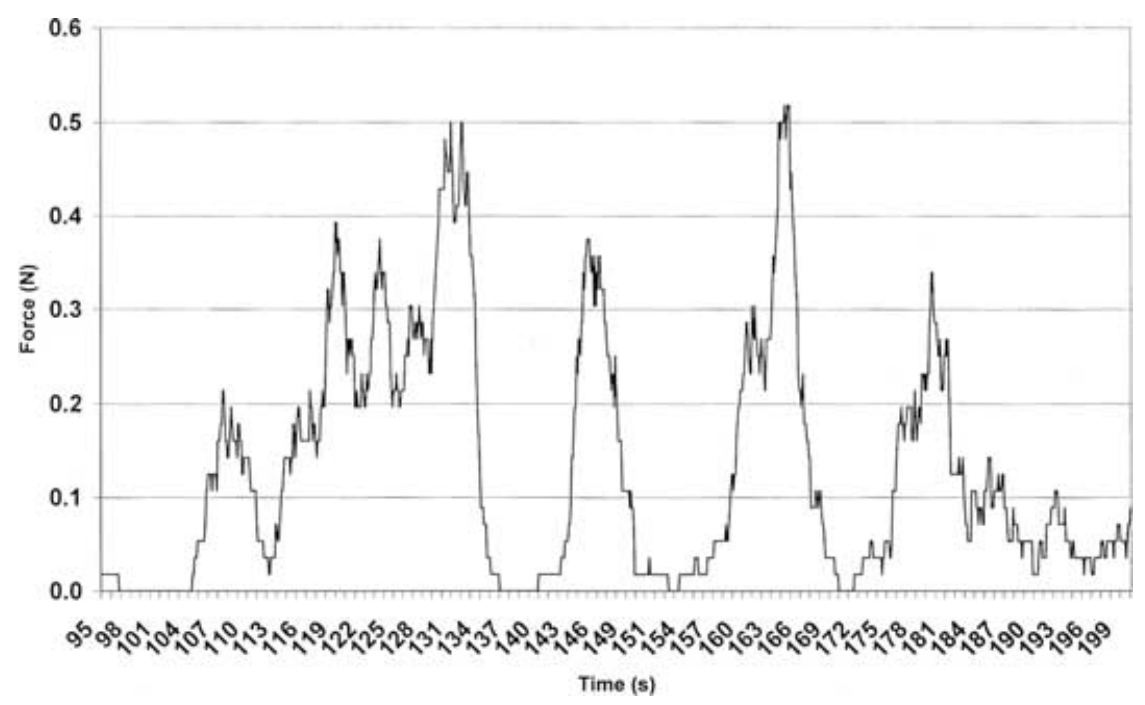

FIGURE 19. Lift-off force induced by engulfed bubbles: STS-77 Run \#5, $q=1$ $\mathrm{W} / \mathrm{cm}^{2}, \Delta T_{\text {sub }}=3^{\circ} \mathrm{C}$.

3. The computed lift-off forces were at times reduced or nonexistant and erratic in behavior.

The variations of the mean heat transfer surface temperatures and the derived heat transfer coefficients are given in FIGURES 4, 6, 8, 10, 12, 14, 16, 18, and 20 for the nine experiments described above, taken directly from Merte et al. ${ }^{1,2}$ These are followed in FIGURES 5, 7, 9, 11, 13, 15, 17, 19, 21 by the corresponding lift-off forces induced by the disappearing or engulfed bubbles, computed from Equation (1).

Estimates of the mean lift-off force as well as the maximum variation are listed in the Appendix for each of the 19 experiments for which these could be evaluated, in order of approximated ascending maximum forces. Also listed, in addition to the nominal values of the imposed heat flux, initial bulk liquid subcooling, and run numbers, are the type of boiling observed and the mean heat transfer coefficients for each of the total 45 experiments.

An attempt was made to determine whether a relationship existed between the lift-off forces here and the Marangoni number, which can be viewed as the ratio of the interfacial surface tension and shear stresses. The expression of Betz and Straub ${ }^{6}$ was used, given as:

$$
M a=\frac{d \sigma}{d T} x \frac{D}{a \mu} x \Delta T_{\text {sub }}
$$




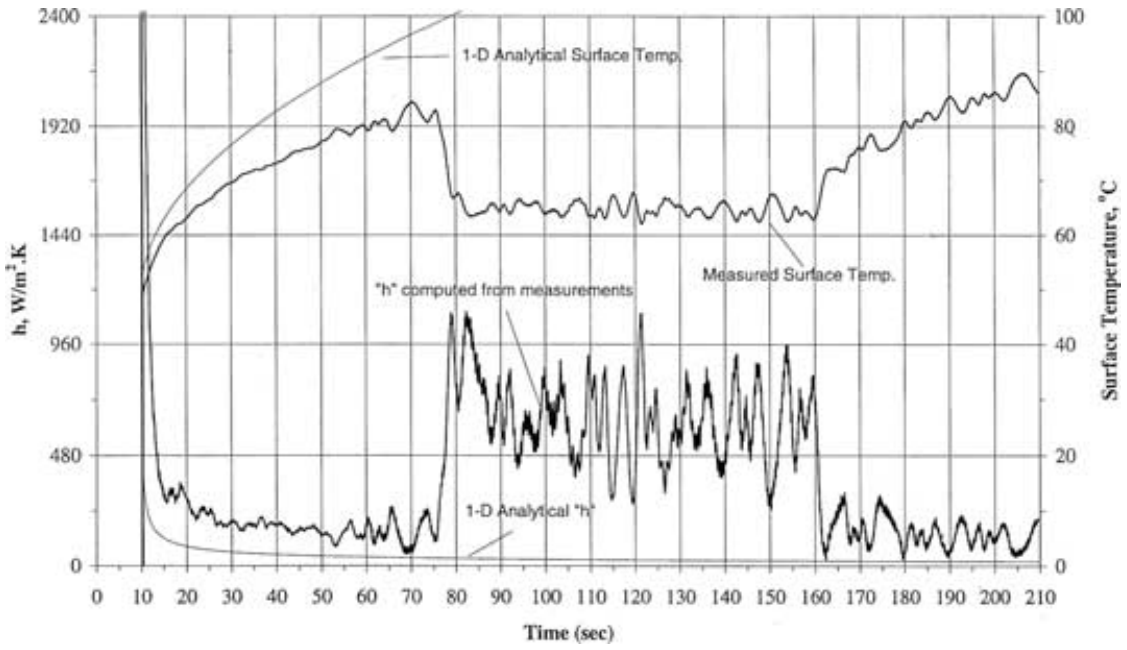

FIGURE 20. Mean heater surface temperature and heat transfer coefficient: STS-77 Run $\# 8, q=1 \mathrm{~W} / \mathrm{cm}^{2}, \Delta T_{\text {sub }}=0.3^{\circ} \mathrm{C}$.

The approximate diameter of the large suspended vapor bubble was taken as the characteristic dimension $\mathrm{D}$, and the initial bulk liquid subcooling was deemed to be a reasonable approximation for the temperature difference driving the thermocapillary process. Using the appropriate physical properties of R-113, the Marangoni number varied over the range $-5 \times 10^{4}$ to $200 \times 10^{4}$, with no consistent relationship to the lift-off forces determined here.

However, it was possible to observe an approximate relation between the pool boiling regimes in microgravity and the imposed conditions of heat flux and bulk liquid subcooling, as given in FIGURE 22. Each circular or oval symbol represents a separate experiment, with the numbers contained within giving the nearest mean integer lift-off forces for steady nucleate boiling, the letters representing the types of nucleate boiling defined in the legend, and the $-\mathrm{x}$ representing the number of repeated behaviors at each condition. Thus, all 45 experiments are included here, and the approximate boundaries between the pool boiling regimes become obvious.

\section{CONCLUSION}

Among the total of 45 experiments conducted of pool boiling on a flat heater surface in the long-term microgravity of space, 26 somewhat unexpectedly resulted in steady-state pool boiling. In each of these, boiling was associated with the formation, growth, and motion of small vapor bubbles, giving rise to average heat transfer coefficients often greater than values obtained in Earth 


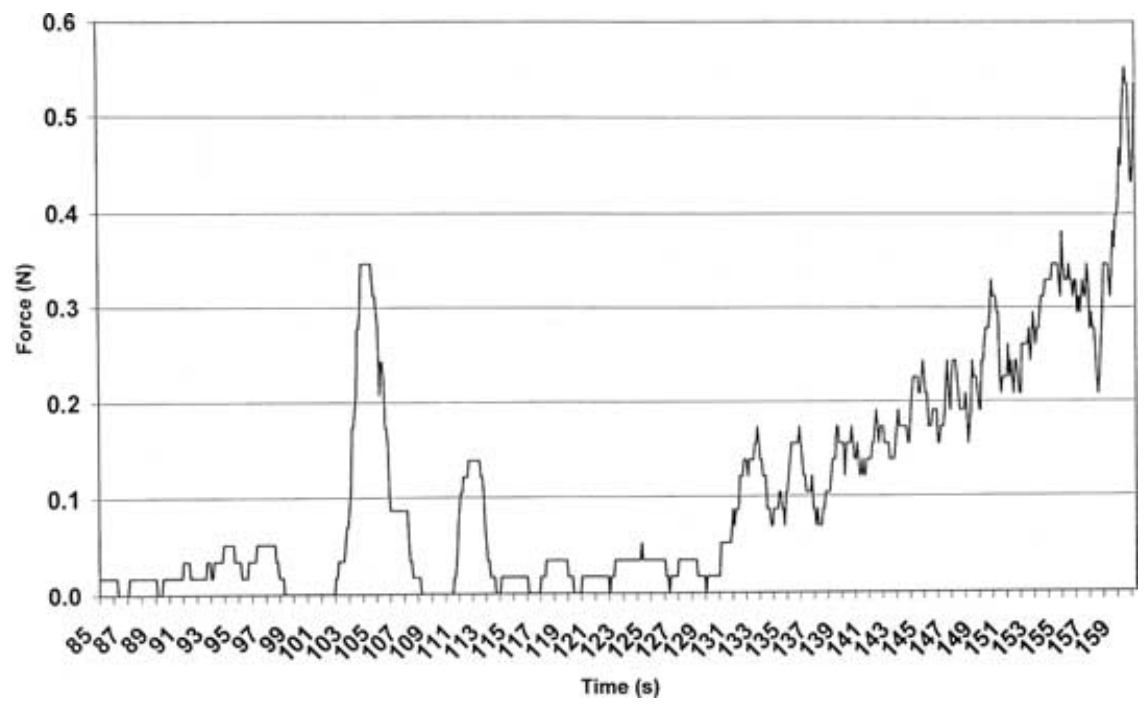

FIGURE 21. Lift-off force induced by engulfed bubbles: STS-77 Run \#8, $q=1$ $\mathrm{W} / \mathrm{cm}^{2}, \Delta T_{\text {sub }}=0.3^{\circ} \mathrm{C}$.

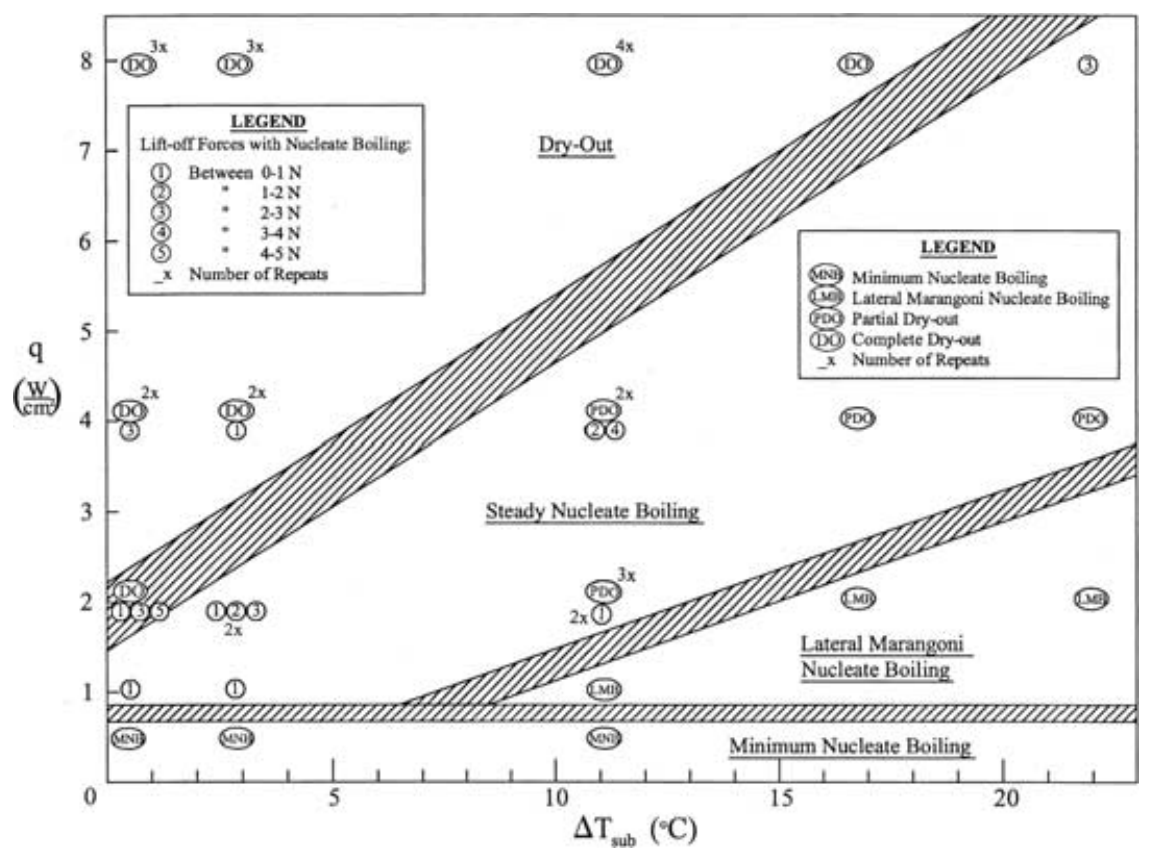

FIGURE 22. Microgravity pool boiling regimes. 


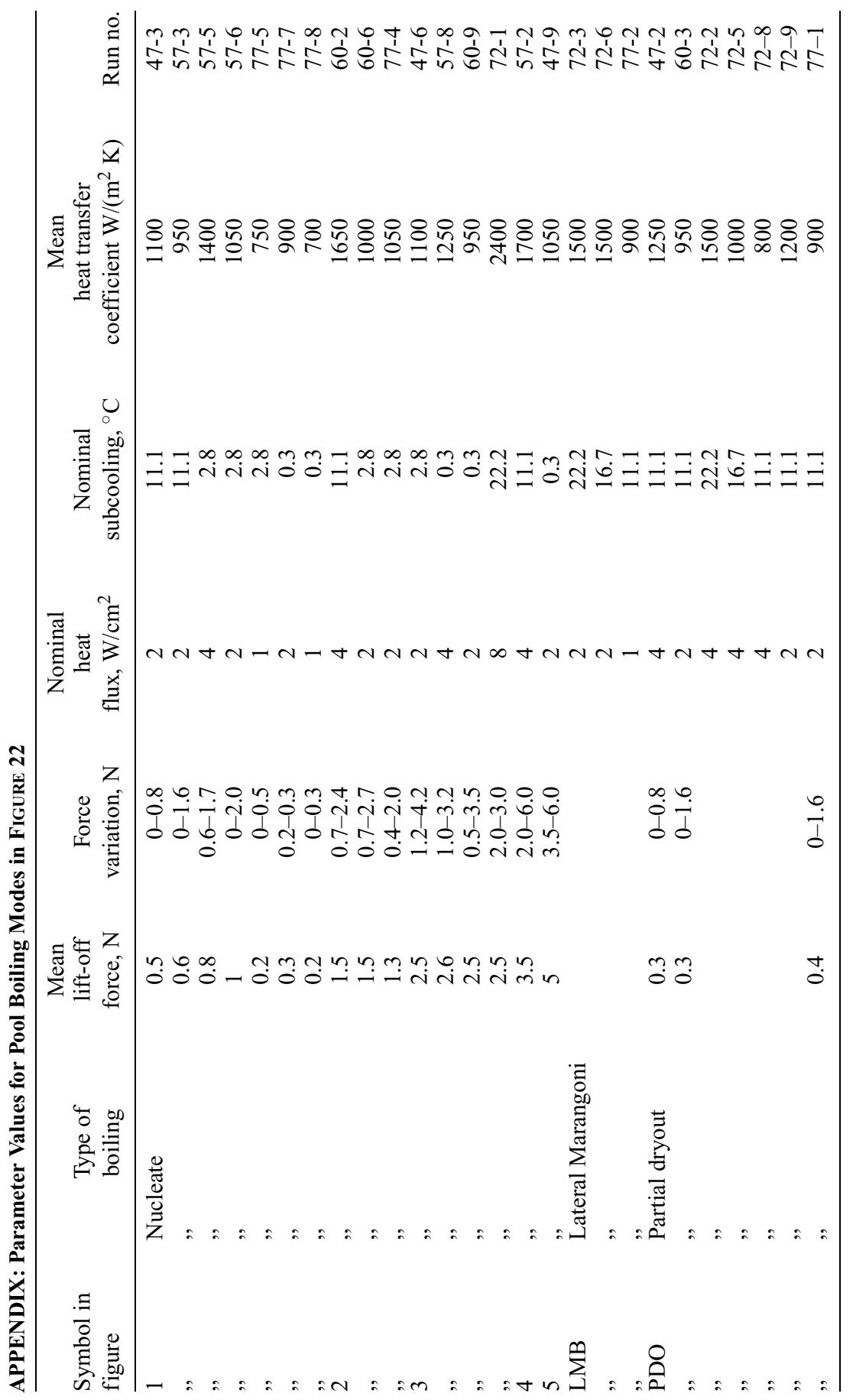




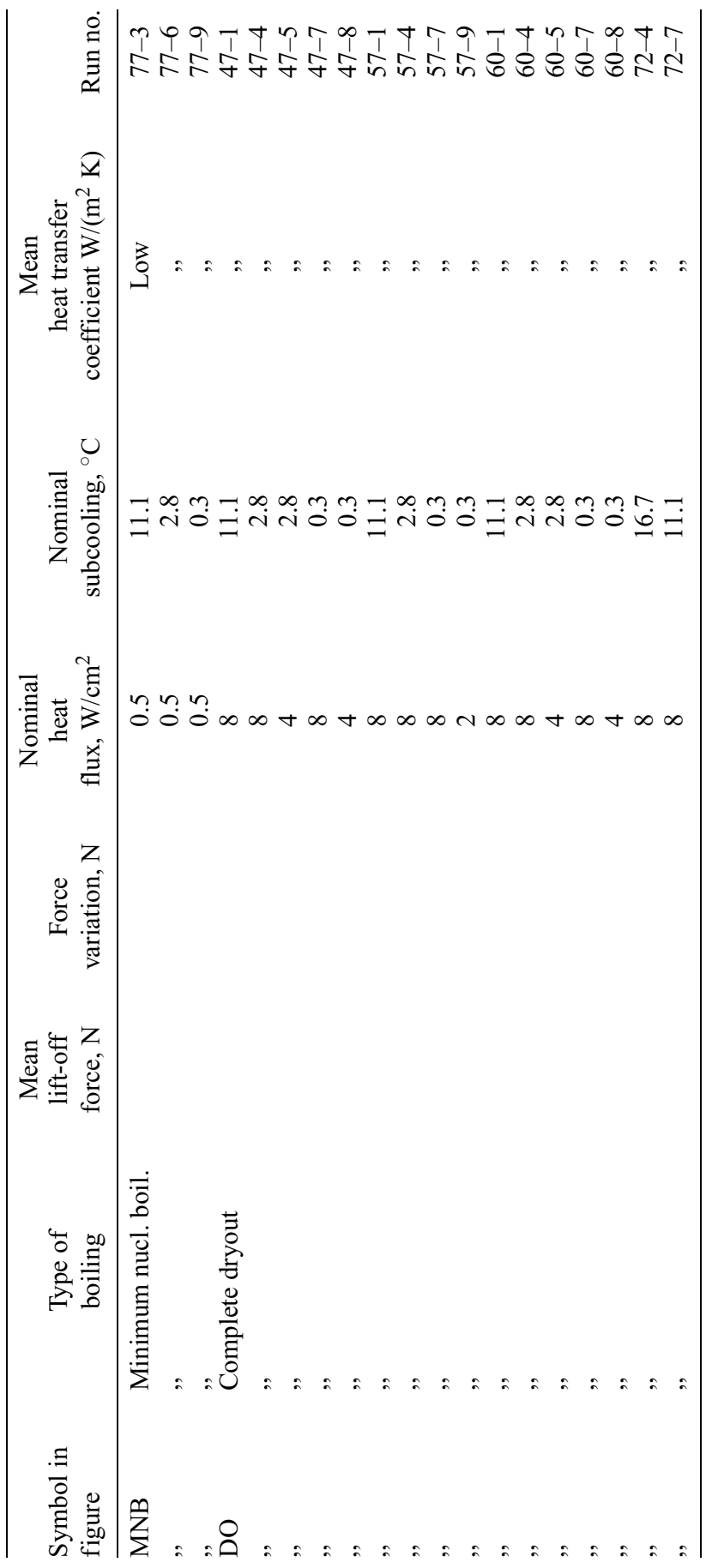


gravity. In 16 of the 26 experiments, the highly effective steady-state boiling takes place when a large vapor bubble slightly removed from the heater surface is present to act as a reservoir for the small bubbles growing beneath. The momentum transfer of these small bubbles to the large one as they combine is believed to provide the force necessary to counter the thermocapillary force, which otherwise would move the large bubble toward the heater surface, resulting in dryout. Measurements of the size and frequency of the small bubbles as they are engulfed by the large one provide estimates of the so-called lift-off force, which counters that of thermocapillarity. Examination of 16-mm motion films showed that 3 of the 26 experiments were associated with relatively high subcooling levels in which the resulting small vapor bubbles remained in the vicinity of the heat surface, with motion parallel to the surface caused by thermocapillary effects. Three of the 26 experiments were associated with such low levels of imposed heat flux that the boiling heat transfer was virtually indistinguishable from the steady conduction process to the liquid. In 16 of the 45 experiments a continuous rise in the heater surface took place resulting from dryout. Partial dryout occurred in the remaining 7 experiments such that steady nucleate boiling was maintained over part of the heater surface, giving rise to a reasonably high average heat transfer coefficient.

The boundaries between these pool boiling regimes are delineated graphically as a function of the imposed heat flux and initial bulk liquid subcooling.

\section{ACKNOWLEDGMENTS}

The results presented here were obtained using films produced under NASA Contract NAS 3-25812 and NASA Grant NAG-1684. The assistance of NASA and Dr. Francis P. Chiaramonte, the Project Scientist at the time, are gratefully acknowledged. The author would like to thank his students, Mr. Eric Preiditsch, Ms. Valerie Toth, Mr. Shawn Burgdorf, and Mr. Jaspar VonBuelow for the, at times, tedious task of measurements from the films.

\section{REFERENCES}

1. Merte, H., JR., H.S. LeE \& R.B. Keller. 1995. Report on pool boiling experiment flown on STS-47 (PBE-IA), STS-57 (PBE-IB), STS-60 (PBE-IC). NASA Contract NAS 3-25812, Report No. UM-MEAM-95-01, Department ofMechanical Engineering and Applied Mechanics, University of Michigan, Ann Arbor, Michigan.

2. Merte, H., JR., H.S. Lee, \& R.B. Keller. 1998. Dryout and rewetting in the pool boiling experiment flown on STS-72 (PBE-IIB), STS-77 (PBE-IIA). Final Report NASA Grant NAG-1684, Report No. UM-MEAM-98-01, Department of 
Mechanical Engineering and Applied Mechanics, University of Michigan, Ann Arbor, Michigan.

3. Merte, H., JR., H.S. LeE \& J.S. Ervin. 1994. Transient nucleate pool boiling in microgravity—some initial results. Micrograv. Sci. Techn. VII/2: 173-179.

4. Lee, H.S., H. Merte, JR. \& F. Chiaramonte. 1997. Pool boiling curve in microgravity. J. Thermophys. Heat Transfer. 11: 216-222.

5. Lee, H.S., H. Merte, Jr. \& F. Chiaramonte. 1998. Pool boiling phenomena in microgravity. Heat transfer 1998. Proceedings of 11th IHTC, Vol. 2, August 2328, 1998, Kyongju, Korea: 395-399.

6. Betz, J. \& J. Straub. 2002. Thermocapillary convection around gas bubbles. Ann. N. Y. Acad. Sci. 974: 220-245.

7. SidES, P.J. 2002. A thermocapillary mechanism for lateral motion of bubbles on a heated surface during subcooled nucleate boiling. J. Heat Transf. 124: 1203-1206.

8. Merte, H., JR. 2004. Momentum effects in steady nucleate pool boiling during microgravity. Ann. N. Y. Acad. Sci. 1027: 196-216.

9. Mastroiani, M.J., R.F. Stahl \& P.N. Sheldon. 1978. Physical and thermodynamic properties of 1,1,2-trifluorotrichloroethane (R-113). J. Chem. Eng. Data 23: 113118. 